\title{
Optimum Autofrettage Pressure for a High Pressure Cylinder of a Waterjet Intensifier Pump
}

\author{
Hakan Çandar*, İ. Hüseyin Filiz \\ Department of Mechanical Engineering, University of Gaziantep, Turkey \\ *Corresponding Author: candar@gantep.edu.tr
}

Copyright $(2017$ by authors, all rights reserved. Authors agree that this article remains permanently open access under the terms of the Creative Commons Attribution License 4.0 International License

\begin{abstract}
This study presents analytical approach for the determination of optimum autofrettage pressure of a thick walled cylinder which is commercially used as a high pressure cylinder of a waterjet intensifier pump. Bilinear kinematic hardening model is used in the derivation of analytical model based on plane strain, Von-Mises yield criteria and incompressible volume assumptions. Elasto-plastic radius is dependent on autofrettage pressure and optimum value of autofrettage pressure is found as a value that will give minimum value of maximum Von-Mises stress on the wall of the cylinder under operating pressure. Hence, considering elasto-plastic radius as the design variable, its optimum value is determined for the specified operating pressure. Reverse yielding owing to Bauschinger effect is used as the only non-linear constraint, Matlab(C) optimtool finds optimum value of the elasto-plastic radius and the corresponding autofrettage pressure is then calculated. By using ANSYS 15C, stress analysis of the autofrettaged cylinder has been performed and the results obtained from both methods are found to be almost the same.
\end{abstract}

\section{Keywords Autofrettage, Kinematic Hardening,} Bauschinger Effect, Optimization, FE Analysis

\section{Introduction}

High pressure cylinders of a waterjet intensifier pump are subjected to an alternating internal pressure at a certain frequency. Failure of these cylinders is due to higher values of alternating stress components at the inner surface. In order to improve fatigue behaviour of these cylinders a compressive residual stress at the inner surface must be created. Autofrettage process is one of the efficient methods using for this purpose. In the autofrettage process, a certain amount of internal pressure is applied to the cylinder so that the inner part of its wall becomes partially plastic. The pressure is then released and the outer elastic part of the wall tries to compress the inner plastic part. Thus, residual compressive stress at the inner surface is achieved.

Analytical model for autofrettage process first proposed by Hill [1] is elastic-perfectly plastic model. Many researchers have been used this model in their studies. Topçu and Filiz [2] compared the performance characteristics of shrink fit and autofrettage process by going through analytical and numerical analysis. Majzoobi et al. [3] studied on the determination of the best autofrettage pressure by going through analytical and numerical analysis. Hojjati and Hassani [4] stated the optimum autofrettage pressure and radius by theoretically and by finite-element modeling based on von misses yielding criteria. Rayhan et al. [5] pointed out that working pressure and the ratio of outer to inner radius effects the optimum autofrettage pressure.

Elastic-perfectly plastic assumption cannot be used for most of the materials due to Bauschinger effect and strain hardening. Huang [6] proposed an autofrettage model considering the material strain hardening relationship and Bauschinger effect, based on actual tensile-compressive curve of material. He found that the smaller Bauschinger effect coefficient causes the reverse yielding to take place more easily and affects the residual stress distribution. White et al. [7] developed an improved isotropic-kinematic hardening model and they defined the Bauschinger effect as one of the most important physical properties to be modelled. EunYeup Lee et al. [8] investigated elasticperfectly plastic and strain hardening models for autofrettaged compound cylinder. They found that the compressive residual stress of the strain hardening model is smaller than that of the elastic- perfectly plastic model because of the Bauschinger effect. Ragab et al. [9] used a generalized material behaviour model includes reverse yielding, non-linear hardening and Bauschinger effect.

In this study, going through the studies mentioned above, an analytical model is generated in order to evaluate the value of the optimum value of elasto-plastic radius so that maximum Von-Mises stress developed on the wall of the cylinder will be minimized under operating pressure. Autofrettage pressure, elasto-plastic radius and operating pressure are all interrelated to each other. Loading the 
cylinder with autofrettage pressure and then unloading the cylinder will create compressive residual stress at the inner surface of the cylinder which will help in reducing the stresses developed under operating pressure. The problem here is to determine the optimum value of autofrettage pressure which gives minimum Von-Mises stress under operating pressure. Due to kinematic hardening behaviour, autofrettage pressure is limited to a value at which reverse yielding begins. This is considered as a nonlinear constraint in optimization process. By using Matlaboptimtool, optimum value of elasto-plastic radius is determined. Optimum autofrettage pressure and corresponding Von-Misses stresses through the wall of the cylinder are then calculated. In order to verify the results, finite element model of the cylinder is created in ANSYS environment and the results obtained from both analytical and FEM analyses are compared.

\section{Theoretical Analysis}

\subsection{Basic Equations}

When a hollow cylinder with closed ends is pressurized as shown in Figure 1, radial stress $\left(\sigma_{\mathrm{r}}\right)$, tangential stress (hoop stress, $\sigma_{\mathrm{t}}$ ) and longitudinal stress $\left(\sigma_{\mathrm{z}}\right)$ are developed. These stresses are the principal stresses. From the force equilibrium on the infinitesimally small element, equation (1) is obtained.

$$
\sigma_{\mathrm{r}}+\mathrm{r} \frac{d \sigma_{r}}{d r}-\sigma_{\theta}=0
$$

And, corresponding strains $\varepsilon_{\mathrm{r}}$ and $\varepsilon_{\theta}$ are given in terms of the radial displacement, $\mathrm{u}$, as:

$$
\begin{aligned}
\varepsilon_{\mathrm{r}} & =\frac{\mathrm{du}}{\mathrm{dr}} \\
\varepsilon_{\theta} & =\frac{\mathrm{u}}{\mathrm{r}}
\end{aligned}
$$
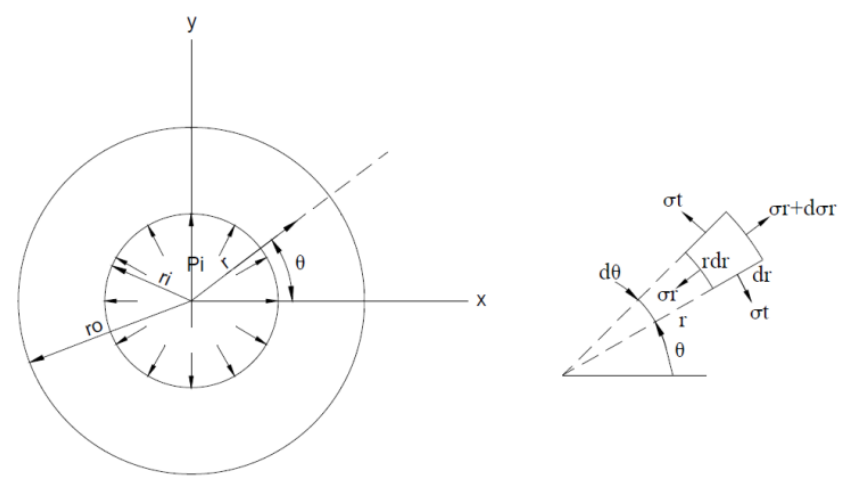

Figure 1. Cross section of a thick walled cylinder under internal pressure
And, the elastic constitutive relations are;

$$
\begin{aligned}
& \mathrm{E} \varepsilon_{\mathrm{r}}=\sigma_{\mathrm{r}}-v\left(\sigma_{\theta}+\sigma_{\mathrm{z}}\right) \\
& \mathrm{E} \varepsilon_{\theta}=\sigma_{\theta}-v\left(\sigma_{\mathrm{r}}+\sigma_{\mathrm{z}}\right) \\
& \mathrm{E} \varepsilon_{\mathrm{z}}=\sigma_{\mathrm{z}}-v\left(\sigma_{\mathrm{r}}+\sigma_{\theta}\right)
\end{aligned}
$$

During autofrettage process, the cylinder is located between two holders that restrict the elongation in longitudinal direction which results plain strain case. Another consideration is about material stress-strain relationship. It is assumed that equivalent stress-strain relationship is the same as stress-strain relationship of simple tension-compression test. In addition to these, incompressible volume assumption $\left(\varepsilon_{\mathrm{r}}+\varepsilon_{\theta}+\varepsilon_{\mathrm{z}}=0\right)$ and Von Misses yielding criteria are used. Von-Mises criterion suggests that, equivalent stress (Von Misses stress) $\sigma_{i}$, and equivalent strain $\varepsilon_{\mathrm{i}}$ are:

$$
\begin{gathered}
\sigma_{\mathrm{i}}=\sqrt{\frac{1}{2}\left[\left(\sigma_{\theta}-\sigma_{\mathrm{r}}\right)^{2}+\left(\sigma_{\mathrm{r}}-\sigma_{\mathrm{z}}\right)^{2}+\left(\sigma_{\mathrm{z}}-\sigma_{\theta}\right)^{2}\right]} \\
\varepsilon_{\mathrm{i}}=\frac{\sqrt{2}}{3} \sqrt{\left[\left(\varepsilon_{\theta}-\varepsilon_{\mathrm{r}}\right)^{2}+\left(\varepsilon_{\mathrm{r}}-\varepsilon_{\mathrm{z}}\right)^{2}+\left(\varepsilon_{\mathrm{z}}-\varepsilon_{\theta}\right)^{2}\right]}
\end{gathered}
$$

For plain strain assumption, $\varepsilon_{\mathrm{z}}=0$, equation (3) gives;

$$
\sigma_{\mathrm{z}}=\frac{1}{2}\left(\sigma_{\theta}+\sigma_{\mathrm{r}}\right)
$$

Substituting equation (6) into equation (4) gives;

$$
\begin{aligned}
& \sigma_{\mathrm{z}}=\frac{1}{2}\left(\sigma_{\theta}+\sigma_{\mathrm{r}}\right) \\
& \sigma_{\mathrm{z}}=\frac{1}{2}\left(\sigma_{\theta}+\sigma_{\mathrm{r}}\right)
\end{aligned}
$$

The radial stress $\sigma_{\mathrm{r}}$ can be obtained from equations (1) and (7);

$$
\sigma_{\mathrm{z}}=\frac{1}{2}\left(\sigma_{\theta}+\sigma_{\mathrm{r}}\right)
$$

And equivalent strain is obtained from equations (2) and (5) and by using plane strain and incompressible volume assumptions;

$$
\sigma_{\mathrm{z}}=\frac{1}{2}\left(\sigma_{\theta}+\sigma_{\mathrm{r}}\right)
$$

Where, $\mathrm{c}$ is integration constant.

\subsection{Stress-Strain Relationship}

In general, materials exhibit different characteristics in elastic and plastic region. In this work, material stress-strain relationship is assumed to be bilinear kinematic hardening model which is shown in Figure 2. The model is considered to consists of elastic region (O-A) and plastic region (A-B) and can be described by two equations. 


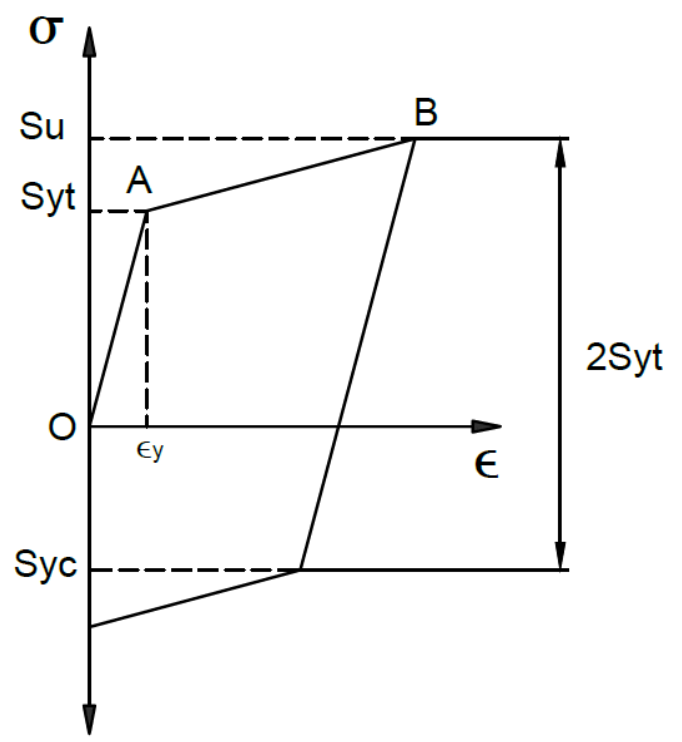

Figure 2. Material stress strain curve based on bilinear kinematic hardening model

Elastic region $(\mathrm{O}-\mathrm{A})$

$$
\sigma_{\mathrm{z}}=\frac{1}{2}\left(\sigma_{\theta}+\sigma_{\mathrm{r}}\right)
$$

Plastic region (A-B)

$$
\sigma=\mathrm{S}_{\mathrm{y}}+\mathrm{T} \cdot\left(\varepsilon_{\mathrm{p}}-\varepsilon_{\mathrm{y}}\right)
$$

Where, $\mathrm{S}_{\mathrm{y}}, \varepsilon_{\mathrm{y}}, \varepsilon_{\mathrm{p}}$ and $\mathrm{T}$ are yield stress, yield strain, plastic strain and tangent modulus respectively. Arranging equation (12) yields,

$$
\sigma=\mathrm{S}_{\mathrm{y}}+\mathrm{T} \cdot\left(\varepsilon_{\mathrm{p}}-\varepsilon_{\mathrm{y}}\right)
$$

Where, $\mathrm{A}$ is a constant and depends on $\mathrm{S}_{\mathrm{y}}, \varepsilon_{\mathrm{y}}$ and $\mathrm{T}$.

$$
\mathrm{A}=\mathrm{S}_{\mathrm{y}}-\mathrm{T} \cdot \varepsilon_{\mathrm{y}}
$$

\subsection{Stress Analysis}

Stresses developed in the loading and unloading stages of autofrettage process are analyzed by using proper boundary conditions. Stresses in the operating stage are considered to be superposition of residual stresses and the elastic stresses due to the operating pressure.

\subsubsection{Loading Stage}

a) Elastic region (O-A)

Substituting equations (10) and (11) into equation (9) gives;

$$
\sigma_{\mathrm{re}}=-\frac{2}{3} \frac{\mathrm{E}}{\mathrm{r}^{2}} \mathrm{c}_{\mathrm{e} 1}+\mathrm{c}_{\mathrm{e} 2}
$$

Substituting equations (10), (11) and (15) into equation (7) gives;

$$
\sigma_{\theta \mathrm{e}}=\frac{2}{3} \frac{\mathrm{E}}{\mathrm{r}^{2}} \mathrm{c}_{\theta 1}+\mathrm{c}_{\theta 2}
$$

Substituting equations (10), (11) and (15) into equation (8) gives;

$$
\sigma_{\mathrm{ze}}=\mathrm{c}_{\mathrm{e} 2}
$$

b) Plastic region (A-B)

Substituting equations (10) and (13) into equation (9) gives;

$$
\sigma_{\mathrm{rp}}=\frac{2}{\sqrt{3}} \mathrm{~A} \ln \mathrm{r}-\frac{2}{3} \frac{\mathrm{T}}{\mathrm{r}^{2}} \mathrm{c}_{\mathrm{p} 1}+\mathrm{c}_{\mathrm{p} 2}
$$

Substituting equations (10) and (13) into equation (7) gives;

$$
\sigma_{\theta p}=\frac{2}{\sqrt{3}} A(1+\ln r)+\frac{2}{3} \frac{T}{r^{2}} c_{p 1}+c_{p 2}
$$

Substituting equations (10) and (13) into equation (8) gives;

$$
\sigma_{\theta p}=\frac{2}{\sqrt{3}} A(1+\ln r)+\frac{2}{3} \frac{T}{r^{2}} c_{p 1}+c_{p 2}
$$

Boundary conditions

The following boundary conditions exist when the cylinder is subjected to internal pressure $\mathrm{Pa}$ as shown in Figure 3.

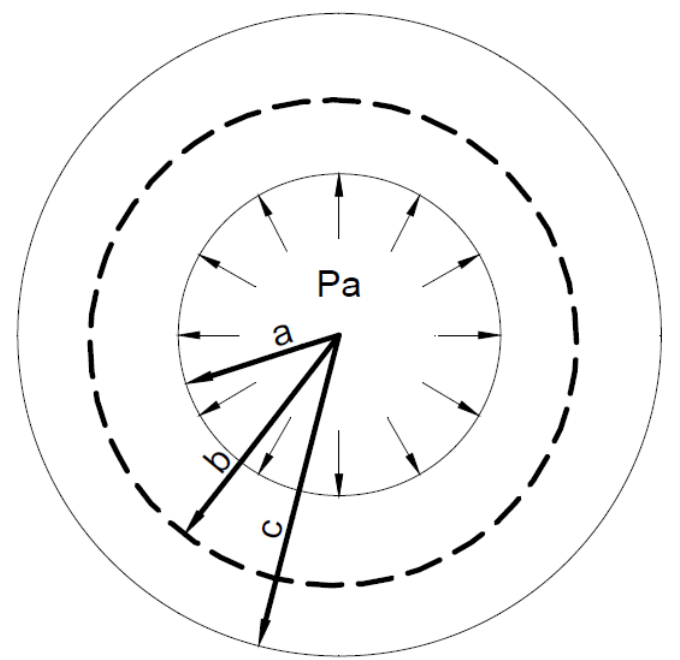

Figure 3. Radii of elastic-plastic zones

1. Both of the equivalent stresses in the elastic zone and plastic zone $(\mathrm{r}=\mathrm{b})$ are equal the yield stress of the material.

a) at $\mathrm{r}=\mathrm{b}, \sigma_{\mathrm{ie}}=\mathrm{S}_{\mathrm{y}}, \mathrm{c}_{\mathrm{e} 1}$ is found as;

$$
c_{\mathrm{e} 1}=\frac{\sqrt{3}}{2} \frac{\mathrm{S}_{\mathrm{y}}}{\mathrm{E}} \mathrm{b}^{2}
$$

b) at $\mathrm{r}=\mathrm{b}$, $\sigma \mathrm{ip}=\mathrm{Sy}, \mathrm{cp} 1$ is found as;

$$
c_{\mathrm{p} 1}=\frac{\sqrt{3}}{2} \frac{\left(\mathrm{s}_{\mathrm{y}}-\mathrm{A}\right)}{\mathrm{T}} \mathrm{b}^{2}
$$

2. The radial stress or at the outer surface $(\mathrm{r}=\mathrm{c})$ and the inner surface $(\mathrm{r}=\mathrm{a})$ are equal to zero and $-\mathrm{Pa}$ (autofrettage pressure) respectively.

a) at $\mathrm{r}=\mathrm{c}, \sigma_{\mathrm{re}}=0, \mathrm{c}_{\mathrm{e} 2}$ is found as; 


$$
c_{e 2}=\frac{1}{\sqrt{3}} S_{y} \frac{b^{2}}{c^{2}}
$$

b) at $\mathrm{r}=\mathrm{a}$, orp $=-\mathrm{Pa}, \mathrm{cp} 2$ is found as;

$$
c_{p 2}=-\frac{2}{\sqrt{3}} A \ln a+\frac{1}{\sqrt{3}}\left(S_{y}-A\right) \frac{b^{2}}{a^{2}}-P_{a}
$$

Loading stress distribution

$$
\text { a) Elastic region (O-A) }
$$

Substituting equations (21) and (23) into equations (15) to (17) gives;

$$
\begin{gathered}
\sigma_{\mathrm{re}}=\frac{1}{\sqrt{3}} S_{\mathrm{y}} \mathrm{b}^{2}\left(\frac{1}{\mathrm{c}^{2}}-\frac{1}{\mathrm{r}^{2}}\right) \\
\sigma_{\theta \mathrm{e}}=\frac{1}{\sqrt{3}} S_{\mathrm{y}} \mathrm{b}^{2}\left(\frac{1}{\mathrm{c}^{2}}+\frac{1}{\mathrm{r}^{2}}\right) \\
\sigma_{\mathrm{ze}}=\frac{1}{\sqrt{3}} S_{\mathrm{y}} \frac{\mathrm{b}^{2}}{\mathrm{c}^{2}}
\end{gathered}
$$

b) Plastic region (A-B)

Substituting equations (22) and (24) into equations (18) to (20) gives;

$$
\begin{aligned}
& \sigma_{r e}=\frac{1}{\sqrt{3}} S_{y} b^{2}\left(\frac{1}{c^{2}}-\frac{1}{r^{2}}\right)-P_{a} \frac{a^{2}}{c^{2}-a^{2}}\left(1-\frac{c^{2}}{r^{2}}\right) \\
& \sigma_{\theta p}=\frac{2}{\sqrt{3}} A\left(1+\ln \frac{r}{a}\right)+\frac{b^{2}}{\sqrt{3}}\left(S_{y}-A\right)\left(\frac{1}{a^{2}}+\frac{1}{r^{2}}\right) \\
& \sigma_{z p}=\frac{1}{\sqrt{3}} A+\frac{2}{\sqrt{3}} A \ln \frac{r}{a}+\frac{1}{\sqrt{3}}\left(S_{y}-A\right) \frac{b^{2}}{a^{2}}-P_{a}
\end{aligned}
$$

\subsubsection{Unloading Stage}

When the autofrettage pressure is totally removed, the unloading will be elastic if there is no reverse yielding. In this case, unloading stresses follow the Lame equations. As a result, residual stresses developed elastic and plastic parts of the cylinder are calculated as;

a) Residual stresses developed in elastic part of the cylinder $(\mathrm{b} \leq \mathrm{r} \leq \mathrm{c})$

$$
\begin{gathered}
\sigma_{r e}=\frac{1}{\sqrt{3}} S_{y} b^{2}\left(\frac{1}{c^{2}}-\frac{1}{r^{2}}\right)-P_{a} \frac{a^{2}}{c^{2}-a^{2}}\left(1-\frac{c^{2}}{r^{2}}\right) \\
\sigma_{\theta e}=\frac{1}{\sqrt{3}} S_{y} b^{2}\left(\frac{1}{c^{2}}+\frac{1}{r^{2}}\right)-P_{a} \frac{a^{2}}{c^{2}-a^{2}}\left(1+\frac{c^{2}}{r^{2}}\right) \\
\sigma_{z e}=\frac{1}{\sqrt{3}} S_{y} \frac{b^{2}}{c^{2}}-P_{a} \frac{a^{2}}{c^{2}-a^{2}}
\end{gathered}
$$

b) Residual stresses developed in plastic part of the cylinder $(\mathrm{a} \leq \mathrm{r} \leq \mathrm{b})$

$$
\begin{array}{r}
\sigma_{r p}=\frac{2}{\sqrt{3}} A \ln \frac{r}{a}+\frac{b^{2}}{\sqrt{3}}\left(S_{y}-A\right)\left(\frac{1}{a^{2}}-\frac{1}{r^{2}}\right)-P_{a} \\
-P_{a} \frac{a^{2}}{c^{2}-a^{2}}\left(1-\frac{c^{2}}{r^{2}}\right) \\
\sigma_{\theta p}=\frac{2}{\sqrt{3}} A\left(1+\ln \frac{r}{a}\right)+\frac{b^{2}}{\sqrt{3}}\left(S_{y}-A\right)\left(\frac{1}{a^{2}}+\frac{1}{r^{2}}\right)
\end{array}
$$

$$
\begin{gathered}
-P_{a}-P_{a} \frac{a^{2}}{c^{2}-a^{2}}\left(1+\frac{c^{2}}{r^{2}}\right) \\
\sigma_{z p}=\frac{1}{\sqrt{3}} A+\frac{2}{\sqrt{3}} A \ln \frac{r}{a}+\frac{1}{\sqrt{3}}\left(S_{y}-A\right) \frac{b^{2}}{a^{2}}-P_{a} \\
-P_{a} \frac{a^{2}}{c^{2}-a^{2}}
\end{gathered}
$$

\subsubsection{Operating Stage}

When the operating pressure is acting, the stresses developed in the cylinder will be reduced due to compressive residual stresses developed at the inner surface of the cylinder.

a) Stresses developed in elastic part of the cylinder under operating pressure $(\mathrm{b} \leq \mathrm{r} \leq \mathrm{c})$

$$
\begin{gathered}
\sigma_{\mathrm{re}}=\frac{1}{\sqrt{3}} S_{\mathrm{y}} \mathrm{b}^{2}\left(\frac{1}{\mathrm{c}^{2}}-\frac{1}{\mathrm{r}^{2}}\right)-\mathrm{P}_{\mathrm{a}} \frac{\mathrm{a}^{2}}{\mathrm{c}^{2}-\mathrm{a}^{2}}\left(1-\frac{\mathrm{c}^{2}}{\mathrm{r}^{2}}\right) \\
+\mathrm{P}_{\mathrm{w}} \frac{\mathrm{a}^{2}}{\mathrm{c}^{2}-\mathrm{a}^{2}}\left(1-\frac{\mathrm{c}^{2}}{\mathrm{r}^{2}}\right) \\
\sigma_{\theta \mathrm{e}}=\frac{1}{\sqrt{3}} \mathrm{~S}_{\mathrm{y}} \mathrm{b}^{2}\left(\frac{1}{\mathrm{c}^{2}}+\frac{1}{\mathrm{r}^{2}}\right)-\mathrm{P}_{\mathrm{a}} \frac{\mathrm{a}^{2}}{\mathrm{c}^{2}-\mathrm{a}^{2}}\left(1+\frac{\mathrm{c}^{2}}{\mathrm{r}^{2}}\right) \\
+\mathrm{P}_{\mathrm{w}} \frac{\mathrm{a}^{2}}{\mathrm{c}^{2}-\mathrm{a}^{2}}\left(1+\frac{\mathrm{c}^{2}}{\mathrm{r}^{2}}\right) \\
\sigma_{\mathrm{ze}}=\frac{1}{\sqrt{3}} S_{\mathrm{y}} \frac{\mathrm{b}^{2}}{\mathrm{c}^{2}}-\mathrm{P}_{\mathrm{a}} \frac{\mathrm{a}^{2}}{\mathrm{c}^{2}-\mathrm{a}^{2}}+\mathrm{P}_{\mathrm{w}} \frac{\mathrm{a}^{2}}{\mathrm{c}^{2}-\mathrm{a}^{2}}
\end{gathered}
$$

b) Stresses developed in plastic part of the cylinder under operating pressure $(\mathrm{a} \leq \mathrm{r} \leq \mathrm{b})$

$$
\begin{gathered}
\sigma_{r p}=\frac{2}{\sqrt{3}} A \ln \frac{r}{a}+\frac{b^{2}}{\sqrt{3}}\left(S_{y}-A\right)\left(\frac{1}{a^{2}}-\frac{1}{r^{2}}\right)-P_{a} \\
-P_{a} \frac{a^{2}}{c^{2}-a^{2}}\left(1-\frac{c^{2}}{r^{2}}\right)+P_{w} \frac{a^{2}}{c^{2}-a^{2}}\left(1-\frac{c^{2}}{r^{2}}\right) \\
\sigma_{\theta p}=\frac{2}{\sqrt{3}} A\left(1+\ln \frac{r}{a}\right)+\frac{b^{2}}{\sqrt{3}}\left(S_{y}-A\right)\left(\frac{1}{a^{2}}+\frac{1}{r^{2}}\right) \\
-P_{a}-P_{a} \frac{a^{2}}{c^{2}-a^{2}}\left(1+\frac{c^{2}}{r^{2}}\right) \\
+P_{w} \frac{a^{2}}{c^{2}-a^{2}}\left(1+\frac{c^{2}}{r^{2}}\right) \\
\sigma_{z p}=\frac{1}{\sqrt{3}} A+\frac{2}{\sqrt{3}} A \ln \frac{r}{a}+\frac{1}{\sqrt{3}}\left(S_{y}-A\right) \frac{b^{2}}{a^{2}}-P_{a} \\
-P_{a} \frac{a^{2}}{c^{2}-a^{2}}+P_{w} \frac{a^{2}}{c^{2}-a^{2}}
\end{gathered}
$$

\subsection{Autofrettage Pressure}

The autofrettage pressure can be obtained by equating radial stress components at elastic plastic interface $(\mathrm{r}=\mathrm{b})$. That is:

$$
\begin{gathered}
\sigma_{\mathrm{re}}=\sigma_{\mathrm{rp}}(\text { at } \mathrm{r}=\mathrm{b}) \\
\mathrm{P}_{\mathrm{a}}=\frac{1}{\sqrt{3}}\left[2 \mathrm{~A} \ln \frac{\mathrm{b}}{\mathrm{a}}+\left(\mathrm{S}_{\mathrm{y}}-\mathrm{A}\right) \mathrm{b}^{2}\left(\frac{1}{\mathrm{a}^{2}}-\frac{1}{\mathrm{~b}^{2}}\right)-\mathrm{S}_{\mathrm{y}} \mathrm{b}^{2}\left(\frac{1}{\mathrm{c}^{2}}-\frac{1}{\mathrm{~b}^{2}}\right)\right]
\end{gathered}
$$




\section{Determination of Optimum Autofrettage Pressure}

\subsection{High Pressure Cylinder of a Waterjet Intensifier Pump}

Intensifier pump is the heart of a waterjet cutting machine and mainly consists of piston assembly, check valve assemblies, low pressure cylinder and high pressure cylinders as shown in Figure 4.
High pressure cylinders are essential part of the intensifier pump where ultra-high pressure (410 $\mathrm{MPa}$ ) develops. In the design of these cylinders, alloy steels are widely used due to some mechanical properties such as high strength to weight ratio, toughness, resistance to fatigue and corrosion. In this intensifier unit AISI 4340 alloy steel is used as the cylinder material. The cylinder has $14 \mathrm{~mm}$ inner, $38 \mathrm{~mm}$ outer radius and $160 \mathrm{~mm}$ length. Chemical composition, mechanical properties and tensile stress-strain relationship are given in Table 1,2 and Figure 5 respectively.

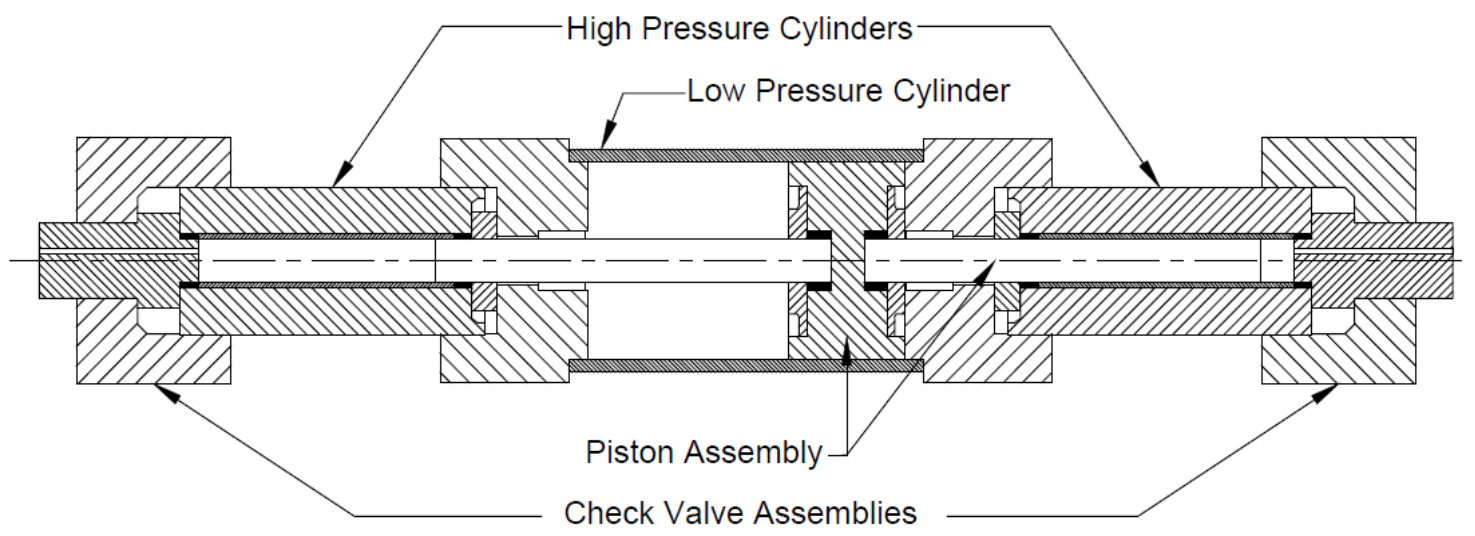

Figure 4. Sectional view of an intensifier pump [10]

Table 1. Chemical composition of AISI 4340 alloy steel [11]

\begin{tabular}{|c|c|c|c|c|c|}
\hline$\% \mathrm{Fe}$ & $\% \mathrm{Ni}$ & $\% \mathrm{Cr}$ & $\% \mathrm{C}$ & $\% \mathrm{Mo}$ & $\% \mathrm{Others}$ \\
\hline 96.6 & 1.8 & 0.8 & 0.4 & 0.25 \\
\hline
\end{tabular}

Table 2. Mechanical properties of AISI 4340 [11]

\begin{tabular}{|c|c|c|c|c|c|c|c|}
\hline Treatment & Syt [MPa] & Syc [MPa] & Sut $(\mathrm{MPa})$ & $\mathrm{E}(\mathrm{GPa})$ & $\begin{array}{c}\text { Tangent Modulus } \\
(\mathrm{MPa})\end{array}$ & $\mathrm{HB}$ & $v$ \\
\hline Q\&T (5100C) oil & 1200 & 1130 & 1270 & 200 & 1489 & 400 & 0.3 \\
\hline
\end{tabular}

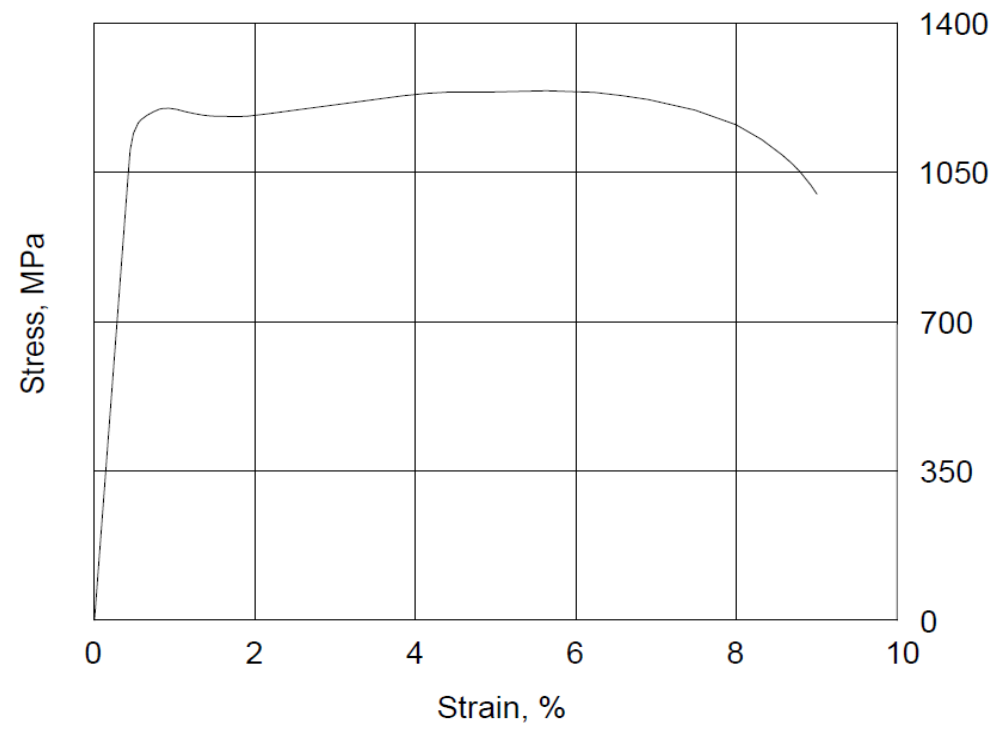

Figure 5. Tensile stress-strain curve of AISI 4340 [11] 


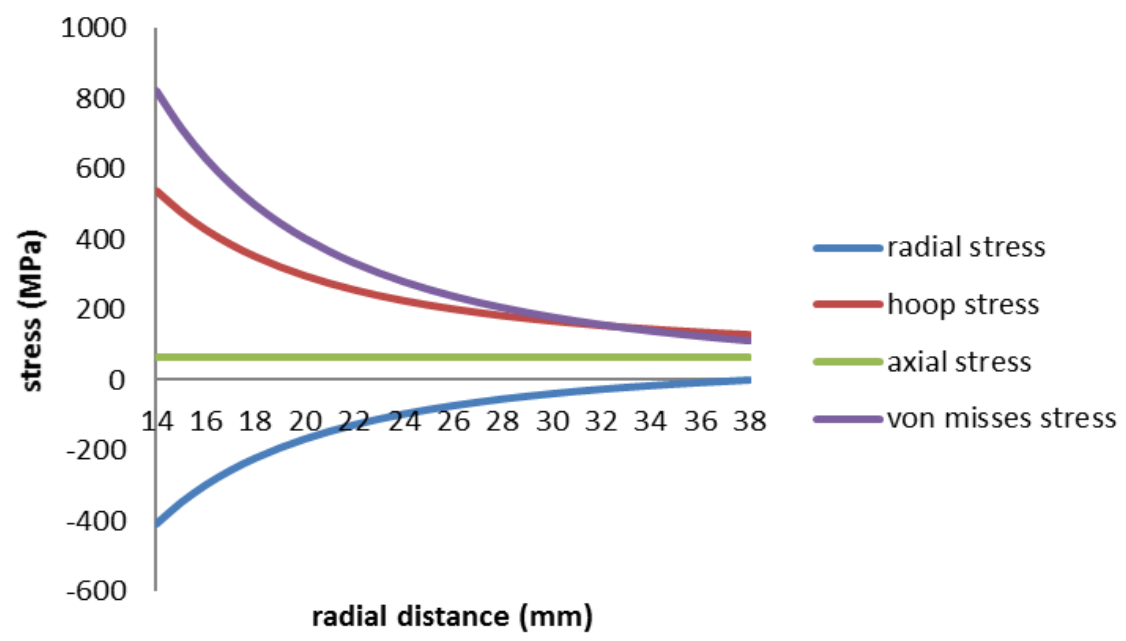

Figure 6. Stress distribution for non-autofrettaged high pressure cylinder under operating pressure of $410 \mathrm{MPa}$

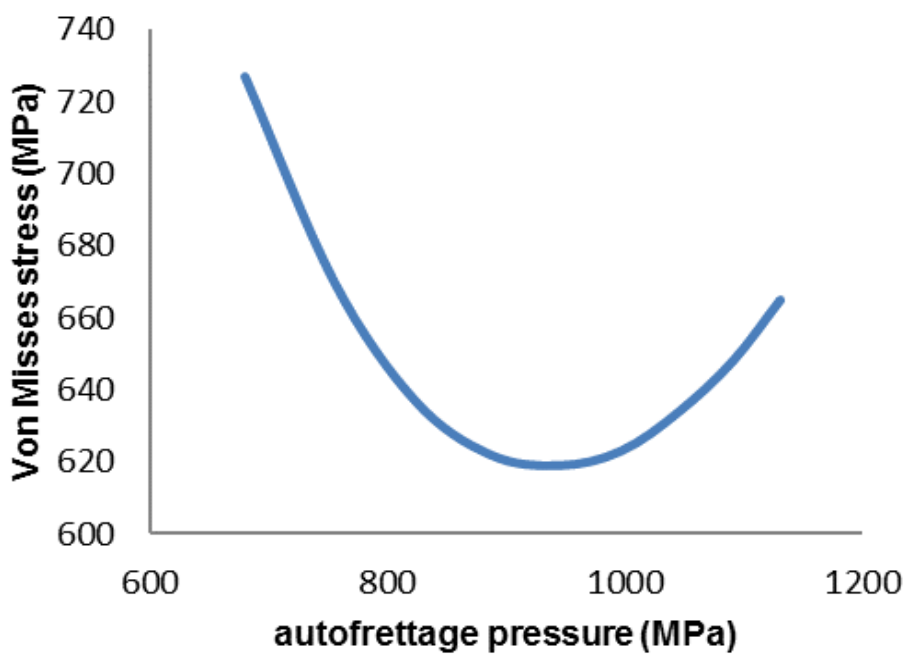

Figure 7. Von misses stress developed at elasto-plastic radius due to operating pressure for different autofrettage pressures

Without autofrettage process the stresses developed through the wall of the cylinder is easily calculated by using Lame equations. Figure 6 represents all stress components of the cylinder under $410 \mathrm{MPa}$ operating pressure. It is seen in the figure that maximum von misses stress $(821,7 \mathrm{MPa})$ occurs at the inner surface of the cylinder. It is actually this stress magnitude which will result fatigue failure for cyclic loading. This level is reduced by the compressive residual stress due to autofrettage process which will result an increase in fatigue life.

\subsection{Optimization}

The amount of autofrettage pressure is to be applied in the wall of the cylinder is an important issue in the autofrettage process. With an increase in the autofrettage pressure, maximum von misses stress at critical section (elasto-plastic radius) in operating stage decreases to a minimum value, but after a specific value of autofrettage pressure it begins to increase as shown in Figure 7.
As seen in equation (43), for a specific cylinder, Autofrettage pressure becomes the function of elasto-plastic radius and the problem is a one variable optimization problem with a nonlinear constraint. By using constrained nonlinear minimization solver with interior point algorithm in MatlabOptimtool the optimum amount of elasto-plastic radius is determined.

After autofrettage process, von misses stress distribution under operating pressure decreases through the wall of the cylinder and the maximum von misses stress occurs at the elasto-plastic radius. Thus, objective function is the minimization of von misses stress at this point and written as;

Minimize, $\mathrm{f}=\sigma_{\mathrm{ie}}=\sigma_{\mathrm{ip}}$, at $\mathrm{r}=\mathrm{b}$

When the autofrettage pressure is removed (unloading stage) residual von misses stress must not exceed yield stress in compression of the material which depends on the amount of strain hardening. Otherwise, reverse yielding starts due to Bauschinger effect. This is a nonlinear inequality constraint and expressed as;

$$
\sigma_{\text {unloading }}^{\prime} \leq S_{\text {yc }}^{\prime} \text { where } S_{\text {yc }}^{\prime}=2 S_{y}-\sigma_{\text {loading }}^{\prime} \text {, at } r=a
$$




$$
\begin{gathered}
\sigma_{\text {unloading }}^{\prime} \leq 2 \mathrm{~S}_{\mathrm{y}}-\sigma_{\text {loading }}^{\prime} \\
\sigma_{\text {loading }}^{\prime}+\sigma_{\text {unloading }}^{\prime}-2 \mathrm{~S}_{\mathrm{y}} \leq 0
\end{gathered}
$$

Another consideration is the lower and upper limits of elasto-plastic radius (b), which must be between inner radius (a) and outer radius (c); $\mathrm{a}<\mathrm{b}<\mathrm{c}$

\section{Results}

From all this considerations, optimum elasto-plastic radius is found as;

$$
\mathrm{b}_{\text {optimum }}=18.862 \mathrm{~mm}
$$

and by substituting it in equation (45), optimum autofrettage pressure is calculated as;

$$
\mathrm{Pa}_{\text {optimum }}=936.260 \mathrm{MPa}
$$

Stress distributions through the wall of the cylinder; loading, unloading and operating stages are given in Figures 8, 9, 10 respectively. Maximum von misses stress is formed at elastic-plastic interface as shown in Figure 10 and it is decreased to $618.93 \mathrm{MPa}$ from $821.7 \mathrm{MPa}$ comparing to non-autofrettaged cylinder.

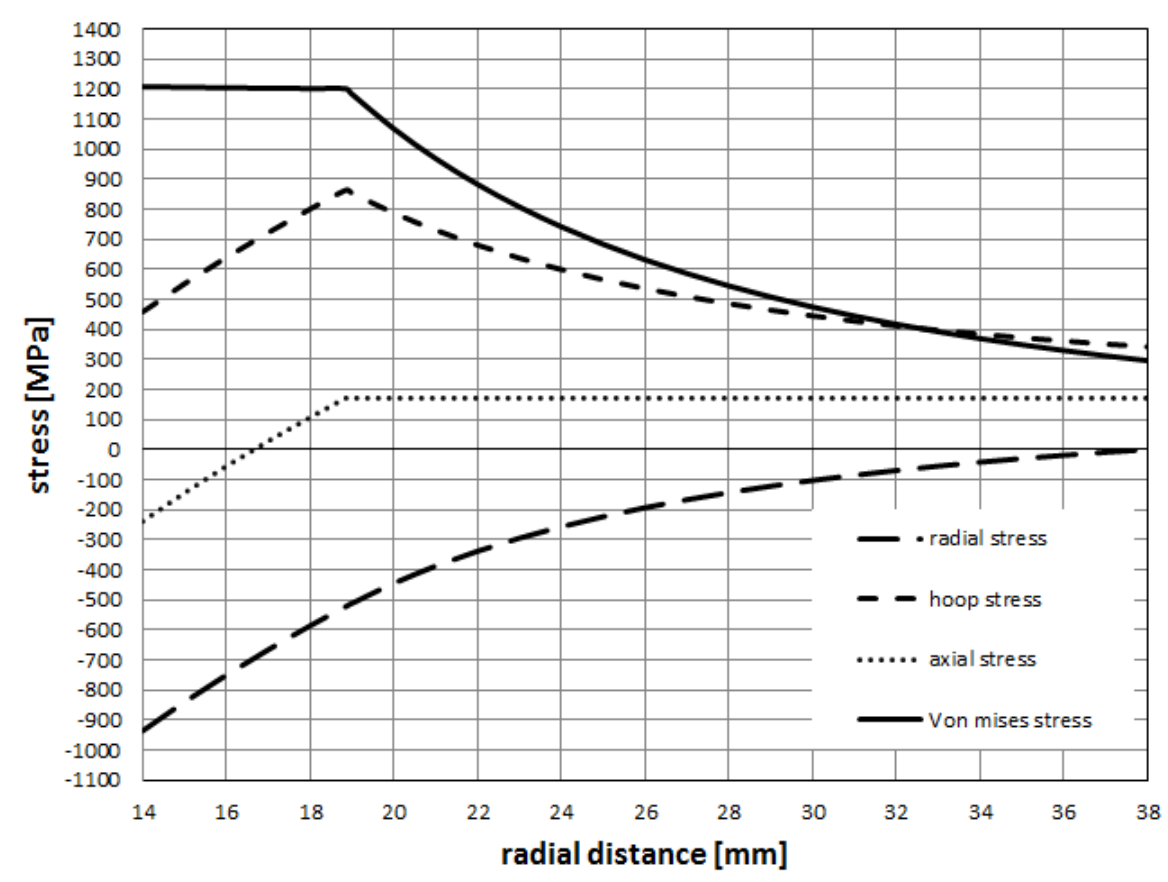

Figure 8. Stress distributions through the wall of the cylinder-loading stage 


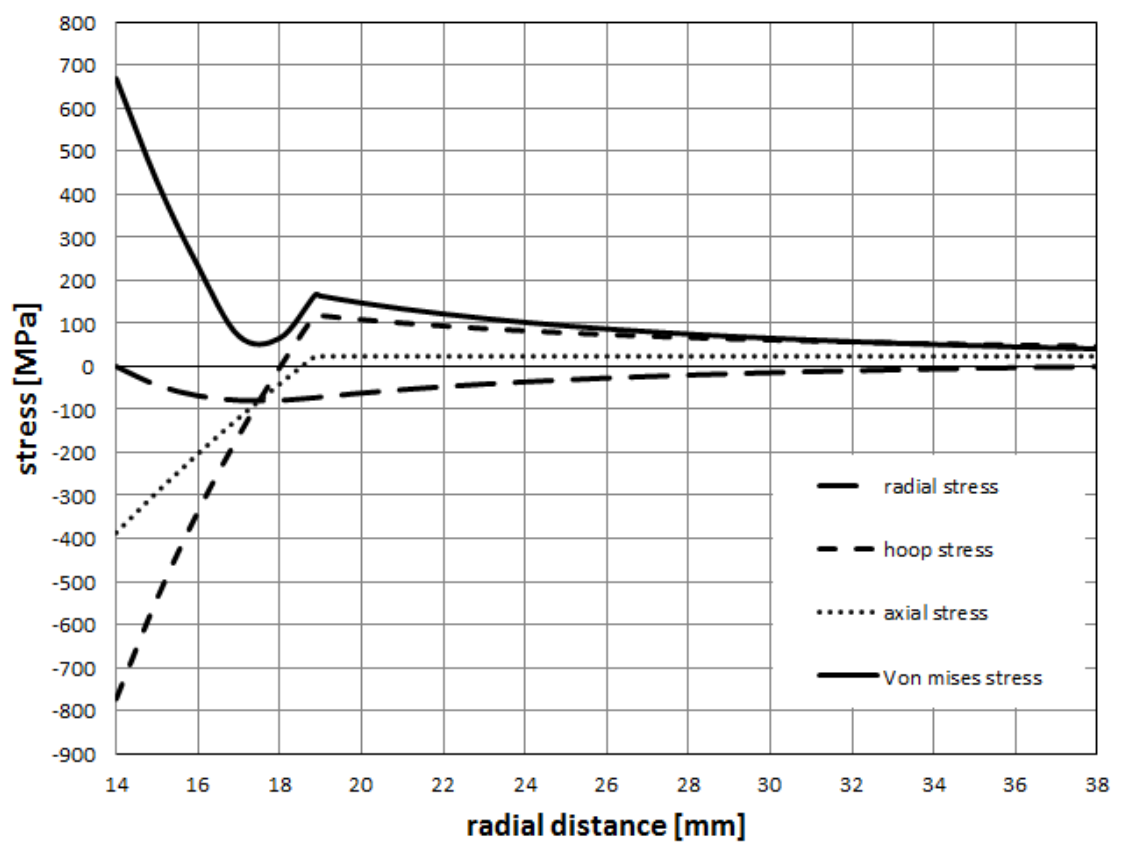

Figure 9. Stress distributions through the wall of the cylinder-unloading stage

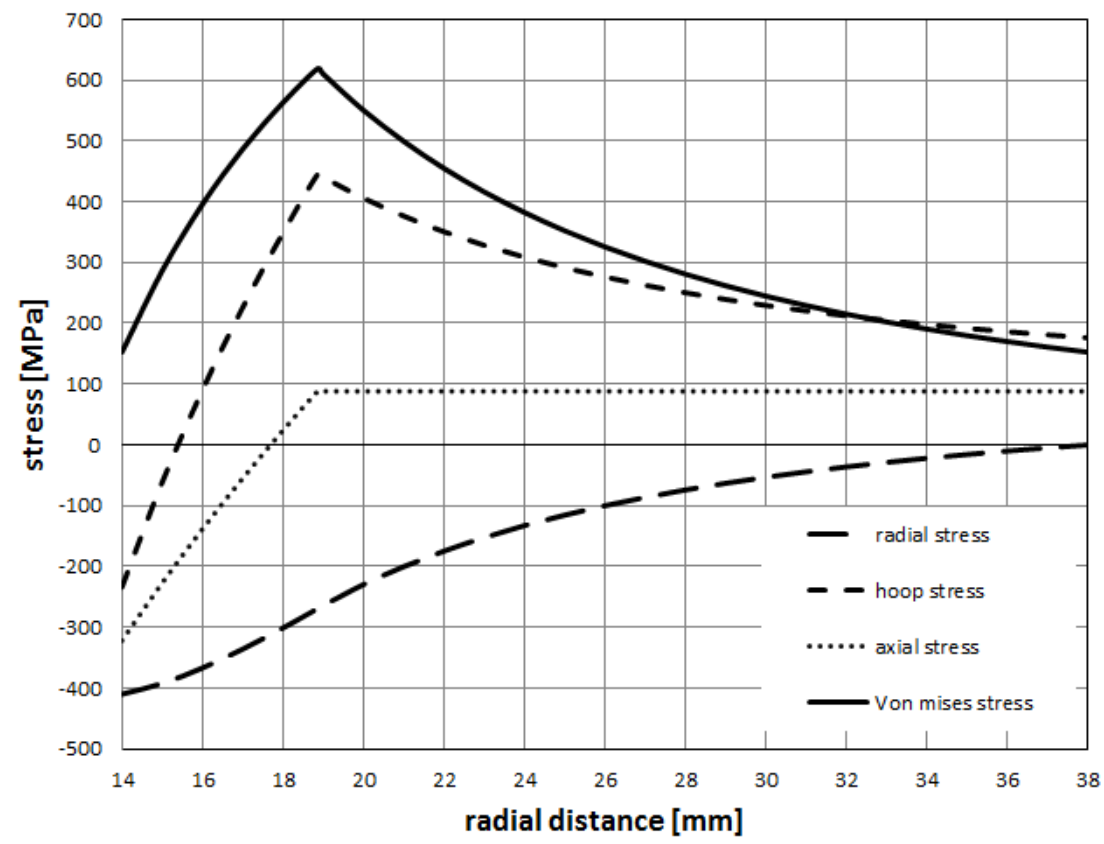

Figure 10. Stress distributions through the wall of the cylinder-operating stage

\section{FEM Analysis}

2D Finite element model is created in ANSYS ${ }^{\circledR}$ Workbench 15.0 to validate the analytical model. Quarter of the cylinder is modeled by using symmetric boundary conditions and plane strain method is selected for the analysis. Uniform and regular meshes are used with $0.1 \mathrm{~mm}$ element sizes. Bi-linear kinematic hardening model is used to describe the stress-strain relationship of the material and the default parameters of ANSYS ${ }^{\circledR}$ are used for the rest.

Analysis is performed in three steps for loading, unloading and operating stages. A path is selected from the inner wall to the outer surface to evaluate the stress values with respect to radial distance along the thickness. Figures 11 to 13 represent the stress distributions for each stage. It is seen that the stress values are almost same with the analytical results; there are only slight differences in axial stress values. 


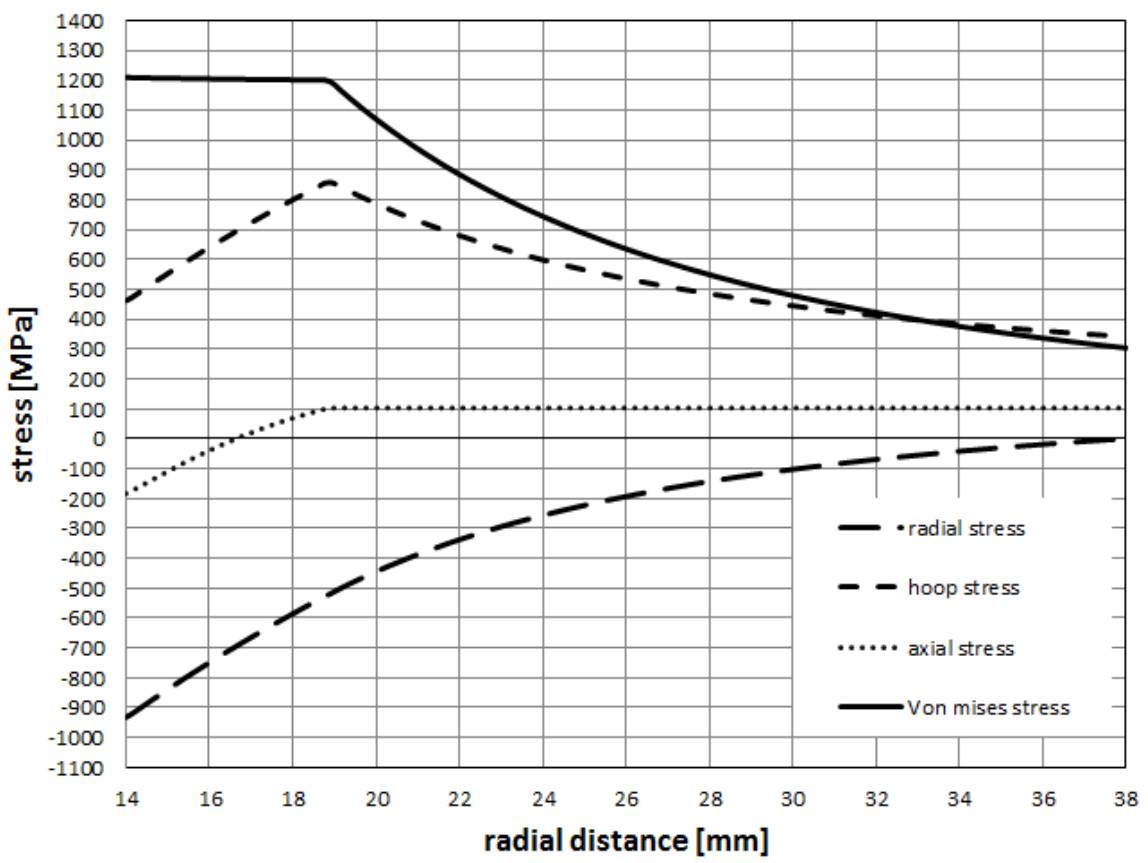

Figure 11. FEM results for all the stress components in the loading stage

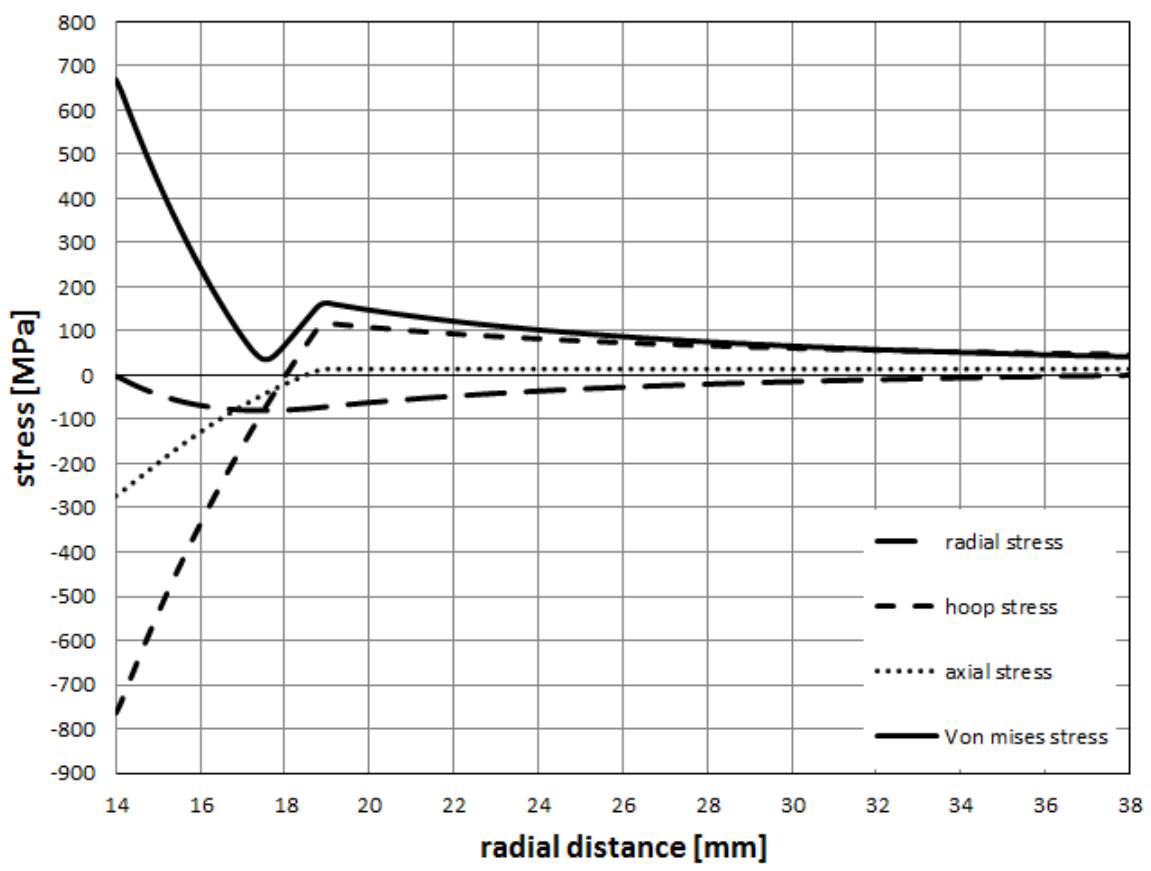

Figure 12. FEM results for all the stress components in the unloading stage 


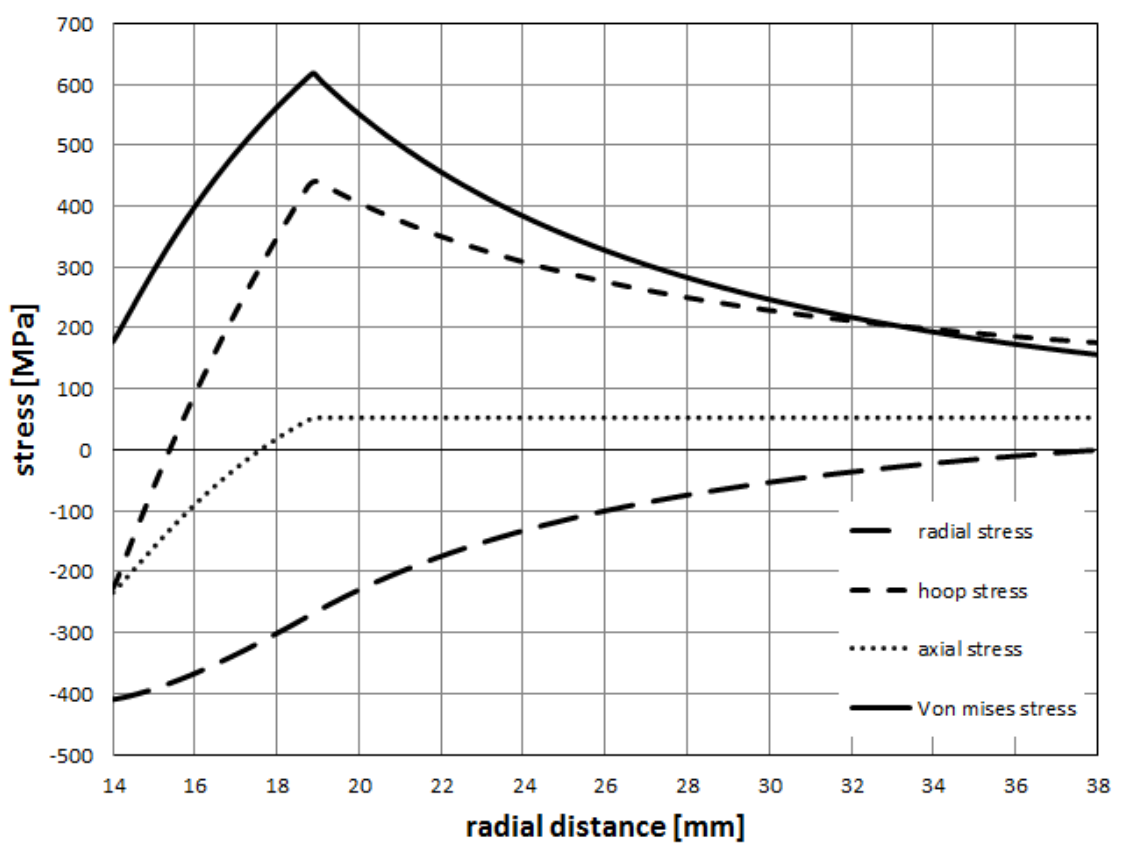

Figure 13. FEM results for all the stress components in the operating stage

Von-Misses stress distributions along the wall of the cylinder for loading, unloading and operating stages are also represented in Figures 14 to 16. In the loading stage, the maximum Von Misses stress is developed on the inner wall of the cylinder is shown in Figure 14, with a value of $1208,8 \mathrm{MPa}$ which is smaller than the ultimate tensile strength of the material $\left(\mathrm{S}_{\mathrm{ut}}=1270 \mathrm{MPa}\right)$. This means that, the pressure value $(\mathrm{Pa}=936.26 \mathrm{MPa})$ can be safely used. After the autofrettage pressure is removed (unloading stage), the maximum Von Misses stress is still developed on the inner wall with a value of 669.31 MPa which is smaller than the yield strength in compression of the material $\left(\mathrm{S}_{\mathrm{yc}}=1130 \mathrm{MPa}\right)$ as shown in Figure 15. When the operating pressure is applied, the maximum Von Misses stress is developed at the elastic-plastic interface as shown in Figure 16 with a value of $618.04 \mathrm{MPa}$ which is almost the same as the analytical result (618.93 MPa).

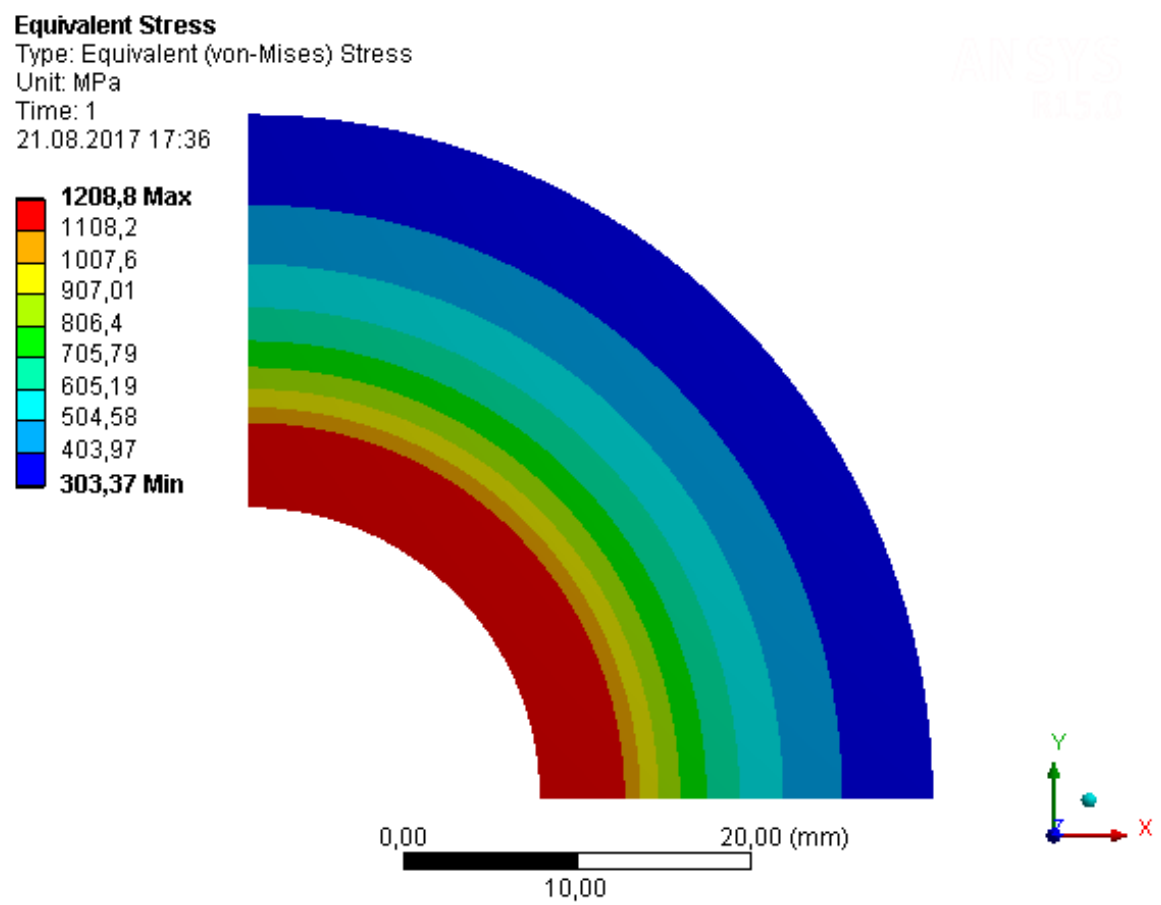

Figure 14. Von Misses stress distribution-loading stage 


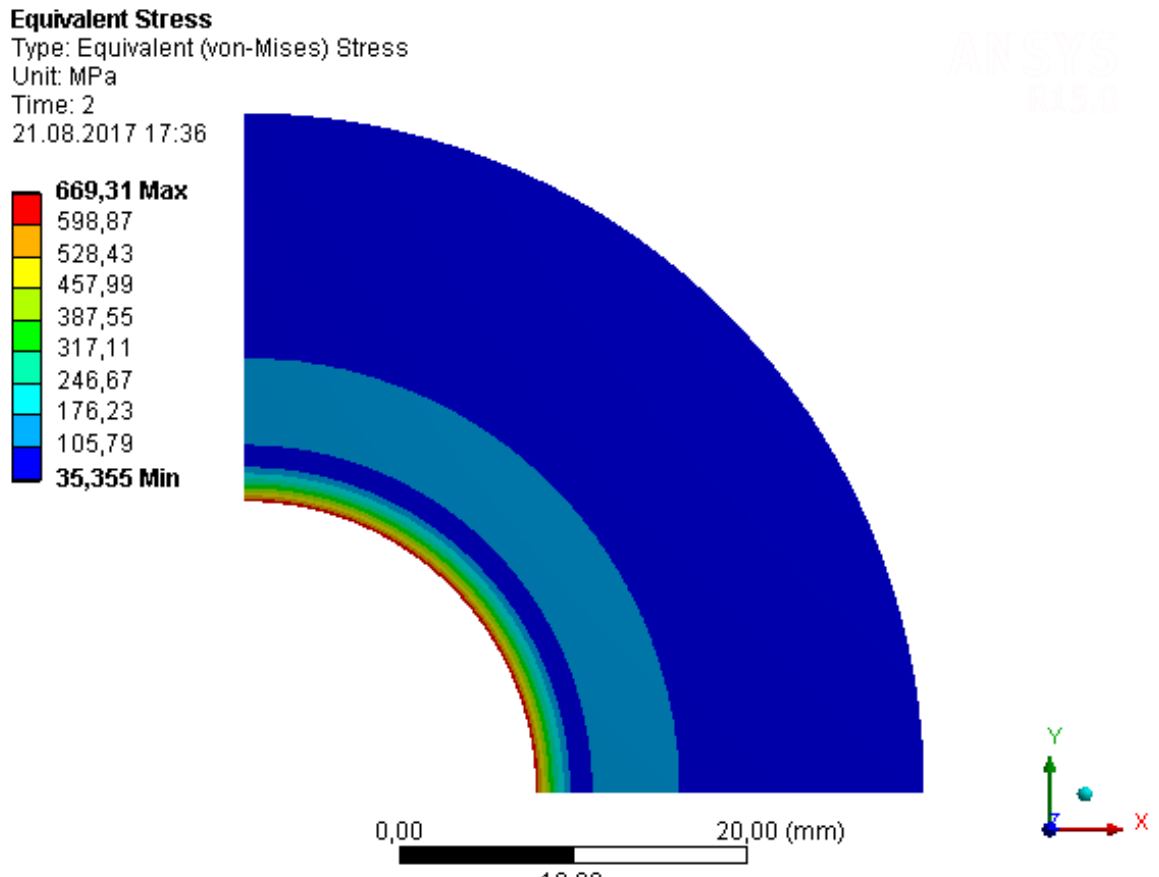

Figure 15. Von Misses stress distribution-unloading stage

Equivalent Stress

Type: Equivalent (von-Mises) Stress

Unit: $\mathrm{MPa}$

Time: 3

21.08.2017 17:34

\begin{tabular}{|l}
$\mathbf{6 1 8 , 0 4}$ Max \\
566,75 \\
515,46 \\
464,17 \\
412,89 \\
361,6 \\
310,31 \\
259,02 \\
207,73 \\
$\mathbf{1 5 6 , 4 5}$ Min
\end{tabular}

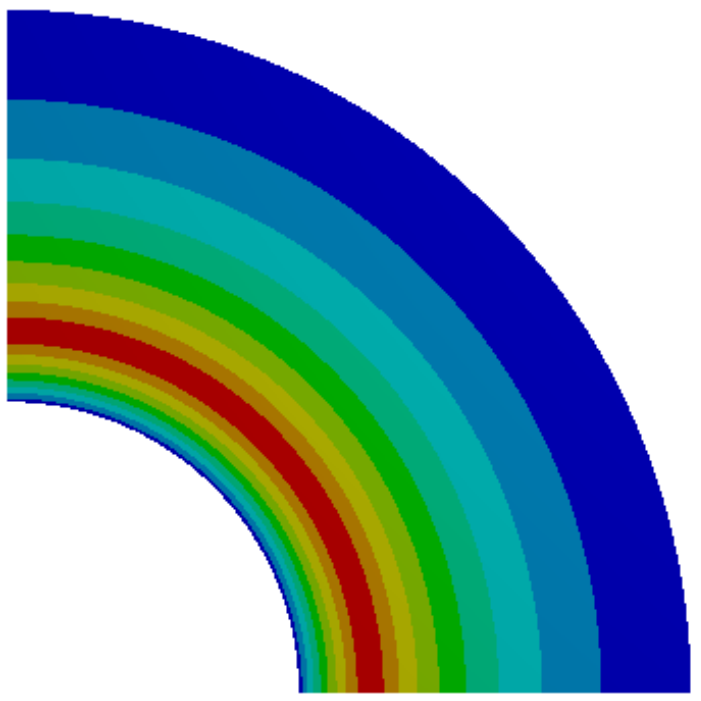

0,00

$20,00(\mathrm{~mm})$

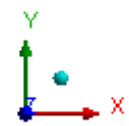

10,00

Figure 16. Von Misses stress distribution-operating stage 
Von Misses stresses obtained from analytical and numerical studies at three distinct places are shown in Table 3. As noticed in this table, the results are almost the same. This indicates that numerical model supports the analytical analysis.

Table 3. Comparison of analytical results with respect to FE results

\begin{tabular}{|c|c|c|}
\hline Von Mises Stress & $\begin{array}{c}\text { Analytical Results } \\
(\mathrm{MPa})\end{array}$ & $\begin{array}{c}\text { ANSYS results } \\
(\mathrm{MPa})\end{array}$ \\
\hline Inner surface & 152.54 & 177.46 \\
\hline $\begin{array}{c}\text { Elasto-plastic } \\
\text { radius }\end{array}$ & 618.93 & 618.04 \\
\hline Outer surface & 152.49 & 156.45 \\
\hline
\end{tabular}

\section{Conclusions}

In this study analytical approach for the determination of optimum autofrettage pressure of a thick walled cylinder is presented. Bilinear kinematic hardening model is used in the analysis. Optimum value of autofrettage pressure is found as a value that will give minimum value of maximum Von-Mises stress on the wall of the cylinder under operating pressure. Considering elasto-plastic radius as the design variable, optimum value of the elasto-plastic radius is found by using matlab $\odot$ optimtool. By using ANSYS $15 \odot$, stress analysis of the autofrettaged cylinder has been performed. The use of analytical approach and finite element method is illustrated with a specific high pressure cylinder. Optimum value of autofrettage pressure and maximum von misses stress in operating stage are found as $936.26 \mathrm{MPa}$ and 618.93 MPa respectively. As illustrated in Table 4, results for both analytical and finite element method are almost the same. In non-autofrettage cylinder, Von-Mises stress was $821.7 \mathrm{MPa}$ which shows the advantage obtained from autofrettage process. The effect of reduction in Von-Mises stress will be seen as an improvement in fatigue behavior of the cylinder.

\section{REFERENCES}

[1] Hill R., The Mathematical Theory of Plasticity, Oxford University Press, New York, 1950.

[2] Topçu F. and Filiz İ.H., Yüksek Basınç Silindirleri Tasarımında Farklı Yöntemler, Makine Tasarım ve İmalat Teknolojileri Kongresi, Konya, 2009.

[3] Majzoobi G., Farrahi G. and Mahmoudi A., A Finite Element Simulation and an Experimental Study of Autofrettage For Strain Hardened Thick-Walled Cylinders, Materials Science \& Engineering, Vol.A359, 326-331, 2003.

[4] Hojjati H. and Hassani A., Theoretical and Finite Element Modelling of Autofrettage Process in Strain-Hardening Thick-Walled Cylinders, International Journal of Pressure Vessels and Piping, Vol.84, 310-319,2007.

[5] Rayhan A.M., Ghosh N.C. and Alam T.E., Optimum Design of Pressure Vessel Subjected to Autofrettage Process, World Academy of Science, Engineering Technology, Vol. 4, 10-26, 2010 .

[6] Huang X., A General Autofrettage Model of a Thick-Walled Cylinder Based on Tensile-Compressive Stress-Strain Curve of a Material, J. Strain Analysis, Vol. 40, 599-607, 2005.

[7] White C., Bronkhorst C. and Anand L., An Improved Isotropic-Kinematic Hardening Model for Moderate Deformation Metal Plasticity, Mechanics of Materials, Vol.10, 1990.

[8] Lee E.Y., Lee Y.S., Yang Q.M., Kim J.H., Cha K.U. and Hong S.K., Autofrettage Process Analysis of a Compound Cylinder Based on the Elastic-Perfectly Plastic and Strain Hardening Stress-Strain Curve, Journal of Mechanical Science and Technology, Vol. 23, No. 12, 3153-3160, 2009.

[9] Ragab A., Abbas A. and Khorshied S., Experimental Verification of the Autofrettage Process for Thick-Walled Tubes, Proc. Instn. Mech. Engrs, Vol. 215, Part C, 727-736, 2001.

[10] Waterjet Component Service INC., Component Report, Majet Su Jeti ile Kesme Sanayi, Biksan Sanayi Sitesi, Istanbul, TURKEY.

[11] ASM International, Atlas of stress-strain curves, Materials Park OH 44073-0002, pp. 108, 2002. 